\title{
Crimean-Congo hemorrhagic fever outbreak in Turkey amid the coronavirus disease 2019 (COVID-19) pandemic; a debacle for the healthcare system of Turkey
}

\author{
Qasim Mehmood MBBS ${ }^{1}$ (1), Muhammad Junaid Tahir MBBS ${ }^{2}$ (1), Abdul Jabbar MPhil ${ }^{3}$ (), Ahsun Rizwan Siddiqi MBBS ${ }^{4}$ (1) \\ and Irfan Ullah MBBS ${ }^{5}$ (iD \\ ${ }^{1}$ King Edward Medical University, Lahore, Pakistan, ${ }^{2}$ Lahore General Hospital, Lahore, Pakistan, ${ }^{3}$ Department of Clinical Medicine, Faculty of Veterinary Science, \\ University of Veterinary and Animal Sciences, Lahore, Punjab, Pakistan, ${ }^{4}$ Pakistan Ordnance Factories Hospital, Wah cantt, Rawalpindi, Pakistan and ${ }^{5}$ Kabir \\ Medical College, Gandhara University, Peshawar, Pakistan
}

To the Editor-Crimean-Congo hemorrhagic fever virus (CCHFV) is a negative-stranded, enveloped RNA virus and is a member of the Bunyaviridae family. ${ }^{1}$ The tickborne viral disease, Crimean-Congo hemorrhagic fever (CCHF), was first identified in Crimea in 1944 and then in Congo in 1969. Since then, many outbreaks of severe viral hemorrhagic fever have been reported in different areas of Eastern Europe, Africa, and central Asia, ${ }^{2}$ with a case fatality rate of $10 \%-40 \% .{ }^{3}$ In the past, serological evidence has also indicated the presence of CCHF in the countries around Turkey, such as Iraq, Iran, Albania, and Russia. ${ }^{2}$

Common clinical symptoms of this acute viral illness include headache, fever, fatigue, extensive bleeding, ecchymosis, petechial hemorrhages, hepatic dysfunction, and generalized body pain. Photophobia, dizziness, myalgia, malaise, abdominal pain, and other gastrointestinal (GI) symptoms have also been reported. ${ }^{2,4}$ No antiviral therapy has proven effective against CCHF but oral ribavirin can be used in severe cases of hemorrhagic fever. ${ }^{1}$ Two vaccines against this virus have been developed by researchers: a formalin-inactivated vaccine and a DNA vaccine. But neither has been recommended for public use until now. ${ }^{5}$

CCHF was first described in Turkey in 2002, followed by 2015 , when $>9,000$ human cases were confirmed. Another CCHF outbreak has occurred in Turkey amid the coronavirus disease 2019 (COVID-19) pandemic. ${ }^{1}$ According to the recent reports of the Turkish Ministry of Health, $>200$ cases of CCHF have been confirmed in Turkey, with 13 human deaths due to this viral disease. ${ }^{3}$ Most of the cases have been detected in the northern areas of central and eastern Anatolia and the central regions of the Black Sea. ${ }^{4}$

Although many genera of ticks can transmit the CCHF virus, Hyalomma marginatum ticks are the primary vectors. ${ }^{3}$ Environmental changes like high temperature, humidity, and precipitation in Turkey may influence the survival and multiplication of the tick population. ${ }^{1}$ Transmission of the CCHF virus occurs either via tick bites or through direct contact with the blood or body tissues of infected animals. Thus, it is more common in rural areas and the people working in livestock industries, agricultural fields, slaughterhouses, and veterinary farms. ${ }^{3}$

COVID-19 was declared a global pandemic by the World Health Organisation (WHO) in March 2020. ${ }^{6}$ The first human case of severe acute respiratory coronavirus virus 2 (SARS-CoV-2)

\footnotetext{
Author for correspondence: Abdul Jabbar, E-mail: vet.drabduljabbar@gmail.com Cite this article: Mehmood Q, et al. (2022). Crimean-Congo hemorrhagic fever outbreak in Turkey amid the coronavirus disease 2019 (COVID-19) pandemic; a debacle for the healthcare system of Turkey. Infection Control \& Hospital Epidemiology, 43: 1726-1727, https://doi.org/10.1017/ice.2021.343
}

infection was detected in Turkey on March 11, 2020, according to the Daily Sabah. As reported by the Health Ministry of Turkey on June 28, 2021, Turkey had had $>5.4$ million confirmed COVID-19 cases, along 49,634 deaths from the virus. A mass vaccination program against COVID-19 began in Turkey on January 14, 2021, after the emergency use of the Chinese Sinovac vaccine was approved by the authorities. More than 33,380,000 people of Turkey have now been vaccinated against SARS-CoV-2.?

Total or partial lockdowns imposed in different regions of the world due to the COVID-19 pandemic have resulted in various epidemics of arboviruses in many countries like Brazil, ${ }^{8}$ Kenya, ${ }^{6}$ and Asia. ${ }^{9}$ The continuous attention of public health authorities toward COVID-19 and the lack of vigilance toward other infectious agents has led to frequent outbreaks in various countries. Healthcare systems in different countries have been exhausted while dealing with the COVID-19 pandemic, which has led to various challenges for healthcare authorities. ${ }^{6}$

The emergence of CCHF in Turkey amid the COVID-19 pandemic has presented various challenges. Recently it has been reported that COVID-19 and CCHF present with similar clinical symptoms and computed tomography (CT) findings. Thus, special care should be adopted while dealing with suspected individuals who present with these clinical symptoms. A typical COVID-19 patient presents with fever, weakness, dry cough, dyspnoea, and loss of smell and taste. Common presentations of CCHF include fever, myalgia, ecchymosis, and extensive hemorrhages. So, CCHF should be included in the differential diagnosis, especially in patients with evidence of ground-glass opacities on chest CT scans in endemic areas. ${ }^{10}$

In Turkey, a female patient was infected with both SARS-CoV-2 and CCHF at the same time. She presented with high-grade fever, fatigue, and respiratory insufficiency, and a treatment process was started first for SARS-CoV-2 and then supportive treatment was given for CCHF. The patient was fortunate enough to recover from both. If extra attention was not given to her case, she would have been treated only for COVID-19 and CCHF would have been overlooked. ${ }^{11}$ Training programs for physicians and healthcare workers (HCWs) are necessary to enhance their awareness regarding early diagnosis, management, and prevention against CCHF. ${ }^{12}$

When all the available healthcare services in Turkey are engaged in dealing with COVID-19 patients, managing patients infected with CCHF is challenging. CCHF patients frequently need hospitalization in well-resourced intensive care units (ICUs), easy availability of blood and blood products, and proper modes of isolation. CCHF patients also need mechanical ventilation in severe cases, which presents challenges because patients with severe 
COVID-19 infection also require ventilatory support. ${ }^{1}$ CCHFV can also be transmitted to HCWs dealing with CCHF patients due to inadequate use of N95 masks, improper hand hygiene, and inappropriate removal of gloves, gowns, and masks after handling blood or tissue products of infected patients.

The WHO should collaborate with the Ministry of Agriculture and Forestry of Turkey to arrange programs to eradicate the tick population in areas where a high number of CCHF cases have been reported. Prevention measures against CCHF outbreaks in Turkey should focus on the education of individuals at increased risk of infection and the supply of personal protective equipment (PPE) to the at-risk population. Awareness campaigns regarding personal protective measures should be encouraged among the general public to avoid tick bites. People should be advised to wear light-colored clothing covering both arms and legs and to use insect repellents to minimize exposure to tick bites. Integration between clinicians and public health workers is required to control all aspects of the outbreak and to manage the growing health crisis in the country.

\section{Acknowledgments.}

Financial support. No financial support was provided relevant to this article.

Conflicts of interest. All authors report no conflicts of interest relevant to this article.

\section{References}

1. Leblebicioglu H, Ozaras R, Irmak H, Sencan I. Crimean-Congo hemorrhagic fever in Turkey: current status and future challenges. Antiviral Res 2016;126:21-34.
2. Karti SS, Odabasi Z, Korten V, et al. Crimean-Congo hemorrhagic fever in Turkey. Emerg Infect Dis 2004;10:1379.

3. Turkey records 13 Crimean-Congo hemorrhagic fever deaths year to date. Outbreak News Today website. http://outbreaknewstoday.com/turkeyrecords-13-crimean-congo-hemorrhagic-fever-deaths-year-to-date-37034/. Accessed June 29, 2021.

4. Zoonotic virus kills 13 since January in Turkey. Daily Sabah website. https:// www.dailysabah.com/turkey/zoonotic-virus-kills-13-since-january-in-turkey/ news. Accessed June 29, 2021.

5. Tipih T, Burt FJ. Crimean-Congo hemorrhagic fever virus: advances in vaccine development. BioResearch Open Access 2020;9:137-150.

6. Mehmood Q, Irfan M, Ogunkola I, Jaguga F, Ullah I. Rift Valley fever and COVID-19 outbreak in Kenya: a double whammy. Ethics Med Public Health 2021. doi: 10.1016/j.jemep.2021.100685.

7. Turkey reports 4,883 COVID-19 cases, 52 deaths. Daily Sabah website. https://www.dailysabah.com/turkey/turkey-reports-4883-covid-19-cases52-deaths/news. Accessed: June 29, 2021.

8. Jain S, Rocha IC, Maheshwari C, et al. COVID-19 in Brazil: the danger of overlapping crises. J Med Virol 2021;93:4090-4091.

9. Harapan H, Ryan M, Yohan B, et al. COVID-19 and dengue: double punches for dengue-endemic countries in Asia. Rev Med Virol 2021;31(2):e2161.

10. Pazarlı AC, Parlak Z, Ekiz T. COVID-19 and Crimean-Congo hemorrhagic fever: similarities and differences. Heart Lung 2020;49:892-893.

11. Woman becomes Turkey's first CCHF, COVID-19 patient, beats both. Daily Sabah website. https://www.dailysabah.com/turkey/womanbecomes-turkeys-first-cchf-covid-19-patient-beats-both/news. Accessed June 29, 2021.

12. Ahmed A, Tahir MJ, Siddiqi AR, Dujaili J. Potential of Crimean-Congo hemorrhagic fever outbreak during Eid Ul-Adha Islamic festival and COVID-19 pandemic in Pakistan. J Med Virol 2021;93:182-183.

\title{
Association between Crimean-Congo hemorrhagic fever (CCHF) and coronavirus disease 2019 (COVID-19): A systematic review
}

\author{
Resat Ozaras $\mathrm{MD}^{1}$ (1), Ahmet Dilek MD ${ }^{2,3}$ (1) , Mustafa Sunbul MD ${ }^{4}$ and Hakan Leblebicioglu $\mathrm{MD}^{5}$ (1) \\ ${ }^{1}$ Infectious Diseases Department, Medilife Health Group, Istanbul, Turkey, ${ }^{2}$ Intensive Care Unit, VM Medicalpark Samsun Hospital, Samsun, Turkey, ${ }^{3}$ Istinye \\ University, Faculty of Medicine, Istanbul, Turkey, ${ }^{4}$ Infectious Diseases Department, Samsun Liv Hospital, Samsun, Turkey and ${ }^{5}$ Infectious Diseases Department, \\ VM Medicalpark Samsun Hospital, Samsun, Turkey
}

To the Editor-We read the paper of Mehmood et al ${ }^{1}$ with great interest. Their letter was based on a newspaper report of novel coronavirus (COVID-19) and Crimean-Congo hemorrhagic fever (CCHF) coinfection, and its scientific basis is questionable.

As cited by Mehmood et al, we previously described the management scheme of CCHF in Turkey in detail. ${ }^{2}$ In 2003, a multidisciplinary advisory board including representatives of Ministry of Health and the Ministry of Food was established. The management of CCHF patients has been carried out in the referral hospitals determined by the Ministry of Health in every region of the country. The virologic diagnosis has been established by the National Reference Laboratory. Records of all CCHF patients are entered into the national CCHF database. Education

Author for correspondence: Hakan Leblebicioglu, E-mail: hakanomu@yahoo.com

Cite this article: Ozaras R, et al. (2022). Association between Crimean-Congo hemorrhagic fever (CCHF) and coronavirus disease 2019 (COVID-19): A systematic review. Infection Control \& Hospital Epidemiology, 43: 1727-1728, https://doi.org/ $10.1017 /$ ice. 2021.388 campaigns were organized for healthcare workers and those engaged in agriculture and animal husbandry in endemic regions. The World Health Organization (WHO), the European Center for Disease Prevention and Control (ECDC), the Food and Agricultural Organization of the United Nations (FAO) and the WHO collaborating Center at Porton Down, United Kingdom, are among the collaborative institutions, and the EpiSouth project, EDENext, ARBO-ZOONET CCH fever, and PREPARE are the networking projects involved in Turkey. ${ }^{2}$ As a result of these measures and studies, the case fatality rate of CCHF is much lower, $4.8 \%$, compared to countries in which CCHF is prevalent such as Pakistan (13.9\%) and Iran (17.6\%). ${ }^{3}$

We agree with the authors' comment that CCHF and COVID-19 have clinical symptoms in common. However, this is universal fact and is not restricted to the cases in Turkey. We performed a search according to the PRISMA guideline, using databases of PUBMED, SCOPUS, and Web of Science, and using the keywords "Crimean Congo Hemorrhagic Fever AND 